Article

\title{
Migration as a Challenge to Couple Relationships: The Point of View of Muslim Women
}

\author{
Monica Accordini, Cristina Giuliani ${ }^{(D)}$ and Marialuisa Gennari * \\ Department of Psychology, Università Cattolica del Sacro Cuore, 20123 Milano, Italy; \\ monica.accordini@unicatt.it (M.A.); cristina.giuliani@unicatt.it (C.G.) \\ * Correspondence: marialuisa.gennari@unicatt.it
}

Received: 30 September 2018; Accepted: 24 November 2018; Published: 29 November 2018

\begin{abstract}
Migration posits new challenges to couple relationships. The distance from one's family and kin, the need to restructure long-standing and culturally established role expectations, the social isolation, and economic strains often put couple stability at stake. Muslim women's perception of the changes that have occurred to their couple relationship after migration has rarely been investigated. To fill this gap in the research literature, a sample of 15 Moroccan and as many Pakistani women living in Italy were administered an in depth semi-structured interview. A thematic analysis of the interview transcripts led to the identification of the following main themes: (a) The value and meanings of marriage; (b) couple life in Italy: Partners' roles; (c) adjustments required by the post-migration context; and (d) resources of the post-migration context. Results show that while migration is often a challenge to couples who are called to renegotiate their values, expectations, and reciprocal duties, it might also be an opportunity to experience a new intimacy far from the control of their family. Moreover, while migration often entails greater autonomy and a more balanced couple relationship for Moroccan women, Pakistanis remain anchored to more traditional gender values and are more exposed to feeling isolated.
\end{abstract}

Keywords: Immigrant couples; Muslim immigrant women; gender role expectations; impact of migration

\section{Introduction}

Migration is a complex, major life event that challenges both individuals and families, and entails a redefinition or adjustment of one's identity, beliefs, values, and expectations [1].

Psychological consequences of migration and resettlement to the new country are probably the most studied topics in the field, both from a psychosocial $[2,3]$ and an ethno-psychiatric $[4,5]$ perspective.

With over 30 million immigrants living beyond their national borders, the integration and acculturation process of Muslim immigrants living in Western countries has been extensively studied, especially after the 9/11 terrorist attacks [6-11]. Acculturation has been defined as "the process of cultural change and adaptation that occurs when individuals from different cultures come into contact" [12] (p. 2). While all immigrants must renegotiate their values, beliefs, and habits to adapt to those of the mainstream society, for Muslims living in Western countries, acculturation also entails additional challenges regarding the clash between conflicting cultural orientations (collectivist versus individualistic) and issues of religious diversity $[8,13,14]$. Moreover, Muslims' acculturation often happens in a context of hostility, prejudice, and discrimination, all factors that have been found to hinder the assimilation process while leading to serious mental health problems and isolation [6,15]. Such difficulties in the integration of Muslim minorities in Western countries have sparked a heated 
debate about the compatibility of Islamic and Western values and lead some to question the very possibility of integration [16,17].

While some scholars have gone so far as to say that integration for Muslims comes at the price of their own cultural identity, see [18], most agree on the fact that acculturation of some kind is the inevitable outcome of immigration, despite the differences between the two cultures $[6,10,19]$. However, while in the past acculturation was believed to be a linear and irreversible phenomenon that would inevitably lead to assimilation and, ultimately, to immigrants being indistinguishable from mainstream society members [20], today, more complex theories have emerged [21,22]. Far from being linear, the process of adjusting to a new culture rather results in a multiplicity of integration patterns and individualized trajectories with periods of positive adaptation and negative stress [6].

Cross-cultural studies identified several variables affecting the acculturation process. Cultural competence, social support, language use and proficiency, length of stay, attitudes towards the host society, and towards traditional values may intervene in hindering or facilitating acculturation $[6,8,9,15]$. Besides such post-migration variables, demographics (e.g., age, gender, education, and occupation) $[9,22]$ and religiosity $[13,14,17,19]$ may also moderate the adjustment to the new society.

There is now extensive consensus on the fact that integration is not a one-way process, but rather the outcome of a transformation that involves both the immigrant and the receiving society $[6,9,21]$.

Keeping into account all the above-mentioned variables, Muslim immigrants' acculturation into Western countries appears to be particularly complex: Not only their collectivistic orientation is in open contrast with the more secularized Western society, but their values and traditions are also deeply rooted in Islamic religion and influence many aspects of their everyday life in ways that are not always considered acceptable by the mainstream society [13]. Specifically, high religiousness has been found to predict attachment to one's cultural identity and to conservative values regarding gender roles and sexuality $[14,19]$; moreover, a negative correlation between religious practices and identification with the host culture has been observed among Muslim immigrants [13].

When gender is considered, things complicate even further: Muslim immigrant women experience a greater degree of conflict between being a Muslim and living in Western society if compared to males [23]. Moreover, Muslim women have been found to fare poorer on key acculturation indicators, such as language proficiency, labor participation, educational attainment, and leisure activities, with respect to both men and their Christian counterparts [10,22]. Encumbered by the pressure of their community to preserve and transmit their cultural values and habits, and, at the same time, subject to pushes towards integration from the host society, Muslim women find it hard to position themselves and renegotiate their representations and beliefs into the new context [22,24]. All such evidences have lead some scholars to believe that Muslim females might be more at risk from acculturation problems than males [16,24]. In this perspective, studies investigating Muslim immigrant women have particularly focused on the acculturation and adaptation strains (e.g., loss of social network and cultural referents, gender role strains, linguistic difficulties, marginalization, and gender and ethic discrimination) experienced in the post migration context see [25-28]. Other studies, however, also highlighted the opportunities offered by living in a new country (e.g., emancipation, greater autonomy, and self-determination) $[25,26]$.

Despite a growing body of literature investigating issues pertaining to Muslim immigrant women, studies on the topic remain scant and mostly written from an individual, rather than a relational, perspective. However, migration also posits new challenges to marital relationships and couple identity, specifically when individuals move from traditional and patriarchal societies to secular and egalitarian ones. Immigrant women's perceptions of the changes that have occurred to their couple relationship after migration have rarely been investigated, with the exception of a few research studies [7,29-31] and some clinical vignettes or essays [32-35]. Moreover, such studies have been written considering Muslim immigrants to North America or Canada while no research has been made on the changes and challenges faced by Muslim couples coming to Europe. While the acculturation path of North 
American and Canadian Muslim immigrants often leads to integration or to the achievement of a bicultural identity, European Muslims encounter greater difficulties in adapting to the host culture and rather adopt a separation strategy, in which a high value placed upon the maintenance of their cultural identity is paired with little or no interest towards the society culture [11,36,37]).

Given the paucity of research studies on the topic, the present explorative study aims at shedding light on the subjective experiences of Muslim women who have immigrated to Italy.

As in many European countries [38,39], Muslim immigrants to Italy are a large and growing minority: It is estimated that about one fourth of the five million immigrants residing in Italy are of Islamic faith [40]. Muslim immigrants to Italy come from over 20 different countries mostly located in Northern Africa (Morocco, Egypt, Tunisia) or in Southern Asia (Pakistan, Bangladesh).

In the present study, we decided to focus our investigation on the post-migration experience of 30 Muslim immigrant women coming from Morocco and Pakistan to explore their perception of the changes that have occurred to their couple relationship following migration. This work employed a cross-sectional qualitative design and presents at least two points of innovation. Firstly, this paper focuses on a relatively unstudied, and yet socially relevant, topic. Secondly, it involves informants from two-extremely different-Muslim countries (i.e., Morocco and Pakistan) with high migration rates towards Italy, especially the North-West area, where this study has been carried out. More specifically, 30 in-depth interviews have been carried out with immigrant women from Morocco and Pakistan. Outcomes revealed a complex and nuanced understanding of immigrant Muslim couples' experiences in Italy: While both subgroups place a high value on marriage and kinship and endorse traditional gender role division, Pakistani women struggle the most in adapting to the new context and report feeling isolated and lacking the support of their female network. On the contrary, Moroccan women show a greater degree of adjustment to the host country, praising the autonomy, independence, and self-determination they are now endorsing.

\subsection{Moroccan and Pakistani Immigrants in Italy}

In Italy, Muslim Arab, North African, and South Asian immigrants account for approximately $20 \%$ of the legalized immigrant population [41,42]. As outlined by recent estimates and projections [39], these immigrants are both younger and have higher fertility rates if compared to the indigenous population, therefore, these figures are deemed to increase, irrespectively of migration flows.

As stated above, Muslims are a heterogeneous group in the Italian context, comprising more than 20 different nationalities. The present study involved two national groups (i.e., Moroccan and Pakistani immigrants), whose presence in the Italian territory is the result of both the need for an unskilled labor force that followed the 1980s' economic boom and the approval of norms regulating family reunifications (Legge Turco Napolitano, Act No. 286/1998).

Moroccans and Pakistanis have different migration histories and characteristics. Migration from North-Africa (i.e., Morocco) began in the mid-1980s, whereas migration from Pakistan (with special reference to the Punjabi area) started in the second half of the 1990s. After having increased steadily for almost two decades (1999-2016), migration rates from these two countries have come to a standstill in 2017. With migration flows on decline, Italy has witnessed a generalized decrease in the number of applicants for residency permits.

Despite this halt in the migration flows, the 454,817 Moroccans and 118,181 Pakistanis officially residing in Italy on 1 January 2017 are among the largest Muslim minorities in the country. In particular, in Italy, Moroccan-born citizens are the largest national non-EU (European Union) foreign group and Pakistanis have been among the fastest growing immigrant groups from 2012 to 2016 [29]. Most of the Moroccan (69.5\%) and Pakistani (71.2\%) immigrants in Italy are living in the Northern part of the country: The former have predominantly settled in urban areas, while the latter live in rural or suburban areas [41,42].

Unlike their Pakistani counterparts, Moroccan communities are much more deeply rooted in the Italian context, as demonstrated by the number of applicants for long-term residence permits $(68.9 \%)$, 
the high birth rates, and the increase in citizenship applications [42]. On the contrary, a significantly lower number of applications for long-term residency permits (51.3\%) is followed by a higher number of citizenship applicants in the Pakistani community, especially among young males.

For both groups, the first migration wave was male-dominated, though this trend has gradually been counterbalanced by the arrival of women and children as a result of family reunification [40]. Despite this new trend, only Moroccan immigrants are balanced by gender whereas a great imbalance in the gender ratios still characterizes Pakistani migration to Italy (about $71 \%$ of the immigrants are males) [41]. Both Moroccan and Pakistani immigrants have a medium-low educational level: $80 \%$ of Pakistanis and $77 \%$ of Moroccans completed only elementary or junior high school. With respect to employment, most of these immigrants perform low-skilled jobs.

Another common trait of these two minorities is the low female labor force participation, with only $21.9 \%$ of Moroccan women and $4.7 \%$ of Pakistani women participating to the Italian labor force (vs. $65.2 \%$ and $70.4 \%$ of Moroccan and Pakistani men, respectively) [43,44].

\subsection{Moroccan and Pakistani Immigrant Women Couple Relationships}

Immigrants from Morocco and Pakistan come from two Muslim-majority countries with different political, socio-economic, and cultural characteristics [45-49].

Morocco is considered to be a wealthier, more developed, and dynamic country with a Gross Domestic Product (GDP) per capita of US \$ 3169; Pakistan, on the contrary, is a poorer country with a GDP per capita of US \$ 1182 [50]. Furthermore, despite the various attempts at improving women's conditions by increasing literacy, promoting female employment, and carrying out social and legal reforms, Pakistani's women's status remains one of the poorest in the world, and both employment rates and access to secondary education are denied to the vast majority of the female population [51].

In both countries, Islam defines a common framework for understanding relevant cultural domains, like marriage and family relations [33,52], although many ethnic, socio-economic, and historical factors affect the ways in which Islamic faith and Quranic norms are interpreted and applied in these countries. Reformist and liberal viewpoints on women's rights have spread throughout Moroccan society, especially following the 2004 adoption of the new Moudawana (the new family code) that introduced a series of measures enhancing women equality in marriage and in other areas of family life [40]. In Pakistan, on the contrary, the co-existence of the Islamic law along with tribal judicial systems contribute to place women in a state of subjugation and hinder the country's modernization process [47].

Despite such specificities and the presence of several ethnic minorities within the immigrant population, a few similarities between immigrants from the two countries considered can be acknowledged.

For both groups, norms regulating marriage, family relations, and social interactions are grounded in a patriarchal power structure and gender role division, and reinforced by Islamic beliefs and teachings.

Family is the key social unit in Muslim societies and family stability and honor are regarded as extremely important values. Honor and modesty are at the core of the family structure; therefore, all members are called to protect family integrity and respectability [53-55]. In this view, family stability and cohesion are deemed as more important than individual needs, thus individual (especially in the case of women) fulfillment and realization is closely tied to marriage and family relations [56]. Women in particular are responsible for keeping the family together, maintaining harmony, solidarity, and loyalty between members $[55,57]$. In other words, women in Islamic countries are the repository of traditional values and habits [58].

Marriage is also given a great importance within Islamic-based communities. While being both a religious duty and a social necessity, marriage grants both spouses' stability and establishes a family. Moreover, by simply marrying, women elevate their status and find their fulfillment as wives and mothers. Marriages also fulfill an important role in maintaining social order and assigning 
each spouse gender-specific tasks and duties. Lastly, marriages tie together two families rather than simply uniting two individuals. In many Islamic countries, families of origin influence, or even determine, their offspring's marital choices. In this respect, consanguineous arranged marriage is a widespread practice in many South-Asian countries, like Pakistan, especially in rural areas and among low-educated individuals [55].

Given the great importance assigned to families of origin and within a context that values modesty and discourages contacts or interactions with people outside the family, young spouses are greatly dependent on their families to solve their disputes and find reconciliation $[59,60]$.

Divorce is disregarded and considered to put shame on the family: While men have easier access to divorce, women willing to divorce their husbands are often stigmatized and socially disapproved $[7,61]$.

Gender segregation and gendered role division of labor are rooted in a patriarchal power structure: Men and women have different and complementing duties and responsibilities [54,62]. While men are in charge of granting the family's financial stability and protection, women's main responsibilities concern housewifery and childcare. In some more traditional countries, such a division translates into segregation while cross-gender interactions are limited or non-existent [56,63]. In this respect, Pakistanis use the term, purdah, to refer to both the veil worn by women as well as the seclusion of women to grant their protection and surveillance [64].

Even with respect to their attitudes and values, men and women in Muslim societies are expected to behave differently: Men should be authoritative while women are encouraged to be submissive and obedient [65]. Such gender specific differences imply that men are in control and entitled to exert authority over their wives. Despite the changes brought about by modernization and the increasing spread of more secular values and beliefs, men in these traditional, male-dominated cultures are still the sole breadwinners and remain largely in charge of making decisions $[33,66]$.

Pakistani and Moroccan women who move to Western countries are faced with many changes in their socio-economic life context (e.g., financial strains, linguistic barriers, social isolation, discrimination) and exposed to more egalitarian and individualistic cultural models. Confronted with a different lifestyle and different ways of perceiving and experiencing family and couple relationships, immigrant women are called to redefine their values and beliefs while adjusting to the new culture $[7,20]$. Literature on this topic has mainly focused on the hindrances and stressors of the post-migration country, and investigated the challenges endured by immigrant women in trying to adjust to the host culture while retaining their heritage values [10,22,32,34,35].

While most research focused on acculturation, trying to identify both the inner (i.e., demographic characteristics, personality traits, religiousness) and contextual (i.e., attitudes of the receiving society, perceived support, or discrimination) factors hindering or facilitating integration, see $[6,9,13,15,19]$, only a paucity of studies have investigated the effects of immigration on the spouses' subjective experiences of their marital relationship [7,30,33,67]. Moreover, research studies have often adopted a deficit theory or a problem-focused approach, thus overlooking the coping strategies put at play by immigrants as well as at the positive changes produced by migration.

For example, much research has been devoted to the understanding of the determinants leading to an increased risk of marital conflicts, family disrupture, and intimate partner violence among immigrant couples [7,54,66,68]. More specifically, inconsistency between one's status and social norms has been found to be associated to higher odds of recurring violence among immigrant men [69]. Moreover, an increased risk of marital conflicts has also been found when spouses held different expectations with respect to their life in the hosting country or had dissimilar acculturation levels [33,56]. Finally, conflicts have been observed in those couples in which an increase in the woman's economic status did not correspond to a parallel change in her husband's gender role beliefs and attitudes [30].

Another relevant, and yet rather unstudied, topic in the migration literature is the impact of the lack of the extended family networks on the immigrant couple relationship. In this respect, both positive and negative effects have been found in the literature. While some researches have 
stressed the increased risk of marginalization and isolation women run as a result of the lack of their extended network [26] as well as on the likelihood for men to recur to deviant or socially unacceptable behaviors $[60,70]$, others have found an increase in mutual dependence, shared decision making, and intimacy among immigrant spouses [7,16,63].

In light of the literature findings outlined above and considering the lack of studies taking into account women narratives and subjective experiences of migration, the present study aims to explore immigrant Muslim women's perceptions of the changes that have occurred to their couple relationship after migration. Specifically, our research aimed at understanding Pakistani and Moroccan women's view on the hindrances and challenges migration posited to their couple relationship as well as on the opportunities and positive changes brought about by this experience.

\section{Materials and Methods}

\subsection{Sample and Procedure}

In depth interviews were conducted with 15 Moroccan immigrant women and as many Pakistani women living in Lombardy, a region in the North-West of Italy. Lombardy was selected for the sample recruitment since it is the Italian region with the highest rate of foreign-born citizens (i.e., 22.4\%) [42].

Moroccan and Pakistani women were selected for this research being, respectively, the largest Muslim immigrant minority overall (30.1\% of all the Muslim immigrants living in Italy) and the largest Muslim immigrant minority of Asian origin (6.1\% of all the Muslim immigrants living in Italy) [71].

Informants were recruited using different methods: Through personal contacts, advertisements at local organizations, schools, and community centers with sizable Pakistani and Moroccan membership, as well as using snowball sampling techniques. To be included in the study, participants had to satisfy the following inclusion criteria: a. Being Pakistani or Moroccan-born; b. Being married to a fellow national; c. Having lived in Italy with one's family for at least two years; and d. Being proficient in Italian.

Before the beginning of the interviews, participants were screened for age, education level, employment status, number of children, and length of stay in Italy. Data are reported in Table 1.

Table 1. Socio-demographic characteristics.

\begin{tabular}{ccc}
\hline Country & Pakistan & Morocco \\
\hline Age & 38.73 & 34.2 \\
Mean & 10.75 & 7.2 \\
SD & & \\
\hline Education (frequency) & 3 & 0 \\
\hline No schooling & 9 & 2 \\
Up to 5 years & 3 & 6 \\
From 6 to 10 years & 0 & 7 \\
>11 years & & \\
\hline Employment status (frequency) & 15 & 11 \\
\hline Housewife & 0 & 3 \\
Part-time job & 0 & \\
Full-time job & & 1.5 \\
\hline Number of children & 3.0 & 1.08 \\
\hline Mean & 1.3 & \\
SD & & 8.53 \\
\hline Length of stay in Italy & 7.42 & 4.88 \\
\hline Mean & 3.57 &
\end{tabular}


All the interviewees (except for two Moroccan women who had moved to Italy together with their spouse) arrived in Italy as a result of family reunification. Despite this similarity, the two subsamples bear some important differences: While all the Pakistani interviewees came from the Punjab area and belong to the Pathan minority, the Moroccan women we interviewed came from both rural or desert areas as well as from major cities in various parts of the country. Moreover, while all the Pakistani women in our sample had more than one child, two of the Moroccan women were childless and four had only one child.

After being informed of the general aims and scopes of the research, interested participants were invited to sign a consent form and interviewed individually by a female researcher with extensive experience in qualitative interviewing and migration-related topics. Gender matching of interviewer and interviewee is believed to facilitate the flow of information and the creation of trust, especially when dealing with immigrants coming from patriarchal-oriented cultures where women are not allowed to voice their feelings and thoughts in the presence of men [72].

The in-depth interviews were conducted at the participant's home or in available public places (i.e., libraries, community centers) and used a semi-structured format aimed at gauging interviewees' perceptions of the changes that have occurred in their couple relationship following migration, their views and expectations with regards to a wife's and a husband's role, and how such expectations have been shaped by migration. While relying on a set of key questions, semi-structured interviews are valuable because they allow researchers to explore subjective viewpoints [73] and to gather insights into people's experiences. The interview questions were piloted with two Pakistani and two Moroccan immigrant women to test for ordering, sequencing, and appropriateness. All the interviews were recorded and transcribed verbatim.

The research was granted approval by the University Ethical Committee (cod.01-14).

\subsection{Data Analysis}

A computer-aided thematic analysis [74] was performed on the interview transcripts using ATLAS.ti 5.0. [75]. ATLAS.ti is a qualitative computer program that can analyze and organize large bodies of textual data. By allowing the researcher to assign codes to text portions, to merge codes into bigger families, and to create and name connections between such families, the programs aids data analysis and allows theory to emerge from data, according to the grounded theory's logic [62]. Data were analyzed by two researchers (i.e., the second and third author) independently and coded for unique and recurrent themes. Each of the coders repeatedly analyzed the transcripts until completing a final code list. The two code lists were then compared and only codes upon which consensus was reached were retained for further analyses, thus resulting in a list of 12 codes. The following step consisted in further merging such codes into meaningful patterns (themes). In this step, codes revolving around the same underlying meaning or topic were grouped together by means of the ATLAS.ti network function [76]. Thanks to such a process, the 12 codes were summarized into five main themes. At this stage, a third researcher (i.e., the first author) analyzed the transcripts again to verify the consistency between each theme and the underlying codes. A subsequent research meeting involving the three researchers resulted in two themes being collapsed, thus generating four main themes. After the coding was completed, researchers leveraged on the ATLAS.ti co-occurrence frequency table to identify related concepts and establish connections between themes [75].

Besides creating connections between different codes and allowing the researcher to name such connections, ATLAS.ti also allows the retrieval of text quotations. Quotations inserted in this paper have been translated into English and the translation-back-translation method was used to determine content validity [77].

\section{Results}

Following, results are presented separately for the two countries considered. A short explanation of each theme is provided along with some extracts from the interviews. 


\subsection{Morocco}

\subsubsection{The Value and Meanings of Marriage}

According to the interviewees, the perspective spouses' families of origin are deeply involved and bound by the engagement and marriage. When partners spontaneously decide to get engaged, as it is the case of the individuals in our sample, the involvement and participation of their families of origin is a duty aimed to preserve their honorability and respectability; in such cases, families usually endorse the engagement, thus making it official.

Following are some quotes that further clarify the above-mentioned concept.

"We had a modern wedding - in that we met and our families agreed to our engagement-and yet, it was a religious wedding, one that abided by the Moroccan traditions."

Far from the romantic connotation it is given in Western countries, the Moroccan wedding is a contract, an agreement between two families, as clearly explained in the following quote:

"Weddings are based on four pillars: an agreement between the parents, a sum of money paid for the bride, men have to pay for everything, women only bring a dowry bed."

In such a context, love is not essential and it is not a necessary prerequisite for the wedding to take place:

"Some fall in love and then get married and some others fall in love after getting married, just like us, we have been together thirteen years."

The wedding ceremony is not only a fundamental step in one's lifecycle, it also marks the entrance into adulthood and as such, it is considered to provide one's life with a meaning and scope, as clearly evidenced by the following quotation:

"People get married because they grow up ... they get married in order to have a family: Having a family is a very positive thing; one simply cannot die without having married, most people wish to marry."

Young couples often happen to live together with the husband's family of origin. However-as reported by two of the couples in our sample-such a forced cohabitation often hesitates in misunderstandings and fights, as couple members are deprived of their privacy and intimacy and feel under constant surveillance. On the contrary, there are also cases in which such a cohabitation results in a strengthening of the relationship between daughters and mothers in law.

Even though habits have changed and women are now allowed to express their opinion and to openly discuss with their husbands, our interviewees still seem to hold onto patriarchal values, according to which women are to obey and be subdued to their husbands' will:

"My mother taught me obedience, she taught me to respect my husband and God ... being a good wife means showing respect towards your husband and God."

Separation and divorce are not an option according to the women in our sample. Even in the face of severe misunderstandings and fights that may result in physical aggressions, a good wife should not leave her husband:

"We are different from the Italians. In Italy, two people may be together for years and then break up, we don't do that: When we decide to get married we stay together for life . . even if there are serious problems, we just stick together." 


\subsubsection{Couple Life in Italy: Partners' Roles}

Migration does not seem to have changed the traditional role division adopted in the country of origin, where men are the main breadwinners and women are expected to look after the children and the house.

Even in the hosting country, a Moroccan woman's role revolves around her being a spouse and mother: It is in the carrying out of such duties that she finds her value and worth. According to the interviewees, when an immigrated Moroccan woman works, she does so out of necessity and to assure her family's financial security.

"Women need to look after the house and the kids, they can't go to work: What if a child is crying and his mother is not around because she's out working?"

Abiding by the religious norms is another way for women to show their modesty and virtue and to pay respect to their husbands. In this view, religion is not valued for its spiritual teachings, but rather for its normative and prescriptive value. Accordingly, migration is often a chance to rediscover religious values and norms that had been forgotten or overlooked in the country of origin. The Moroccan women's discomfort and sense of estrangement experienced in encountering a different, and often distant, culture is therefore often resolved with a return to more traditional values and habits, seen as providing protection and belonging.

Wife: "When I got here and saw how women are used to dress and behave, I understood the importance of wearing a veil."

Interviewer: "So it was your choice to wear the veil."

"Yes, it was my choice."

Interviewer: "So, back in Morocco you did not used to wear the veil."

Wife: "No, I didn't. My brothers told me I should wear it, but back then I didn't want to wear it."

The importance of abiding by the religious norms as a sign of modesty and respectability also translates in the interviewed women severely criticizing the overt sexualization and abuse of the female body in the Western culture and media. By the same token, many interviewees condemned the women's push towards self-fulfillment to the detriment of taking care of the family.

"Italian women in the media are really too much ... also at the sea ... this is really inappropriate, these women are not fit to be seen, they don't show any respect, they are being sexually provoking and it is definitely not appropriate, especially in public. When women behave like this they offend their families and husbands too."

Despite the persistence of traditional gendered values in the immigrants' representations of their couple life, everyday needs often lead women to experience greater deals of autonomy and freedom and to perform tasks traditionally attributed to men or shared with the family (i.e., finding a job, dealing with the medical and bureaucratic procedures, managing the relation with the school). Such an increased independence is generally tolerated, as it is perceived as necessary to the family functioning.

"Mine have been really good parents, but they failed to understand the importance of education. I want to be different, I chose not to wear the veil and to work and I am happy with my choice... you can still be a good wife."

Free from the control and surveillance of their families of origin, immigrated Moroccan couples must learn to set their disputes and fights on their own. In this sense, migration taught some couples the art of negotiation: Far from their families and community, spouses have to turn to one another in search of understanding and support and learn to handle their differences. 


\subsubsection{Adjustments Required by the Post-Migration Context}

Even though the above-mentioned greater independence and autonomy gained by women in the migration country is often not a choice, but rather an inevitable consequence of the adjustment to the new context, it may lead to a marked change in the couple dynamics in terms of a more balanced and equal role division. Women are now acknowledged as a social and negotiation competence and therefore choices and decisions need to be shared and agreed by both spouses.

"Italian couples have different habits, here [in Italy], women decide on behalf of their husbands, for us, Moroccans, it is not like that, we are just starting to share decisions about some issues."

"When I am in Morocco I don't smoke, I am not allowed to get out without his permission, I don't wear trousers or make-up and I only wear long dresses, and my head is always covered."

Men are also subject to a relevant change after migration: Women in our sample reported viewing their husbands as more open, flexible, and more capable of attending to their needs. It must be noted that a few men have also been reported to help with house chores due to their wives' heavy workload outside the home.

These changes inevitably led to a constant, albeit unconscious, modification in the couples' power dynamics.

"Now we are starting all over again because he realized that I am talking a lot more here while I was not used to talk much before, I would just remain silent, I didn't have anything to say. On the contrary, now I am talking too much, maybe it is something I have been hiding inside; before I didn't have much freedom ... it is a new start for us."

Only three of the women in our sample reported to have replicated the same models, behaviors, and attitudes their parents had among themselves in their own couple. As shown in the text extracts reported below, these women are the ones that seem to suffer the most from the lack of the extended family and community network.

"We did not change our habits and stick to the same customs we had in Morocco and here in Italy we struggle..."

"We are experiencing a lot of difficulties ... life is not the same."

"It is not as it was in my own country. Back there I could do ... I could go wherever I wanted to, I was free to go around with my family."

Despite the positive changes brought about by migration, almost all the interviewees reported problems in adjusting to the Italian context and experience of a sense of loneliness and isolation. However, in only one case did such feelings result in clinical depression. The harsh impact with the host country led most women to recall their own land with nostalgia and to depict it in idealized terms.

\subsubsection{Resources of the Post-Migration Context}

Although presenting them with many stressors and difficulties, according to the interviewed women, life in the post-migration context is also charged with opportunities and positive changes. In this respect, while parting women from their families of origin and community, migration also entails the end of a, often difficult, forced cohabitation with their spouses' family. Reuniting with their spouses in Italy gave these women the chance to subtract themselves from the control and surveillance of their husbands' family while finally being responsible for their own choices.

"When he was in Italy and I was waiting for the papers to join him I used to stay with his family.

Days were so long ... it was really hard, first of all because I was far from him and then because I was 
staying with a family I knew nothing about ... it was terrible, definitely not pleasant. Since your husband is not there, you need to ask for permission to do anything, if you want to go out, you need to ask them first and if you do something, they'll always give their opinion, that may be different from yours."

Along with the diminished control and interference from the families of origin, life in the post-migration context often leads to a more balanced couple relationship. Not only can tasks and responsibilities now be shared between spouses, they can also experience a greater closeness and intimacy.

"When we are here [in Italy ed.] we behave differently, we indulge in intimacy and share confidences with each other, back there [in Morocco ed.] we are different, more distant."

Migration is also praised for the economic opportunities it can open to Moroccans. While allowing them to support their families back in the homeland, life in Italy also gives Moroccan couples the chance to grant their children a better future.

"We are happy here in Italy: We have a house and a job and our kids are happy too. When your kids are happy and you have enough money to support your family then you don't need anything else. Money is very important, this is the reason why my husband decided to come here with all the family."

\subsection{Pakistan}

\subsubsection{The Value and Meanings of Marriage}

Islamic faith and traditional values are at the core of Pakistani weddings. Conceived as contracts between families, engagements and weddings constitute a fundamental developmental task in people's lives. As it was the case for the Moroccan sample, love is not deemed to be a necessary element for a good marriage and separation or divorce are not viable options. Despite these similarities, Moroccan and Pakistani women bear several differences in the ways they perceive and think of their couple life.

Contrarily to what happened for the Moroccan women, all the Pakistani interviewees had an arranged marriage and only some of them were asked their opinion about the partner their parents had chosen, as explained by the following interviewee:

"In our country, our parents are responsible for organizing the wedding, they choose the right girl for their son. They go and visit different houses until they find the right woman for their son. They look for someone with the same economic status, the same attitudes and views, and evaluate her behavior... Sometimes the girl is considered to be ok, but her parents are not and so the wedding does not happen."

Pakistani weddings are, therefore, a family rather than an individual matter, this is especially true since brides become effective members of their husbands' families while often relinquishing the relations with their own parents. For such reasons, many women report having felt sad or scared on their wedding day:

"When you get married you lose your family and you have to take care of your husband's family, under every aspect".

"The wedding day is the saddest day for a girl ... you enter a new family and you never know how it will be".

"I had never seen him before [the wedding ed.], I hadn't had the chance to talk to him or his family until I went living with them, so I didn't have the chance to understand their attitude ... you only understand such things after some time... so I was scared". 
Marriage gives a woman's life a meaning and scope: Women get married to have children, continue the family lineage, and are expected to take care of the elderly and, in general, to look after their husbands' extended families. As explained by a Pakistani woman:

"According to our religion, when a man turns 18 he needs to find himself a wife, he needs to marry. The same is true for a girl when they reach 17 ... they need to start their own family and help both their family of origin as well as their husband's family ... it's a parent's duty to find a suitable man ..."

Back in their homeland, Pakistani men and women have specific and distinct roles and therefore spend most of the day apart from each other while being supported in their chores and activities by people of their gender:

"In our culture, women work all day amongst themselves; men, on their side, work and go around together and maybe they get home late in the night, at one in the morning ... and women need to wake up early, so they have different schedules and they are both free!"

\subsubsection{Couple Life in Italy: Partners' Roles}

Pakistani women immigrated to Italy maintain their own culture of origin as they hold onto the traditional values and principles acquired in their homeland. Among such values is the higher importance of the extended family over the nuclear one. Extended families are the pillars upon which each individual's life is based, despite the cultural changes due to immigration. Often the women in our sample underlined the loyalty towards their family of origin and their profound bond with their parents, who continue to be a role model and whose wishes and needs are a priority:

"Sometimes if something's wrong between us we try to sort it out, but if we don't succeed, then the only person who can is his father or his mother [the husband's parents ed.] ... if it's something really serious, my parents will jump in too to save the marriage."

In such a perspective, women often report being preoccupied over their elderly parents' health for fear of not being able to assist them or to send the money they had promised:

"Parents are extremely important to us and we do as they teach us, always ... I learned how to be a mother and a wife from them."

"I am worried because I don't get to see my family, I am not there if they need something, I can't help them or ask my husband to give them something or to go and visit them if they are in need".

In case of difficulties or choices to be made, immigrated women turn to their parents and obey the will and directives they have received from the previous generations. Family bonds are therefore renewed and acquire strength through actions and rituals that reactualize them even in the host country, as shown by the following statement:

"If something's wrong your parents are not here to tell you what to do ... I think of what my mother used to tell me and I try to do it".

The rigid, gendered role division typical in the Pakistani society is kept without much variations once in Italy; women are called to take care of the children and the house while men are responsible for ensuring the family's financial stability. It is also a male's duty to protect women, for example, preventing them from looking at inappropriate images or listening to improper discourses on the Italian media. Women, on their side, remain locked in the safety of their homes and only go out with their husbands or older sons. In this respect, all the interviewees stated that the family and couple models used in Pakistan have been replicated in Italy with no substantial modification:

"It's the same ... either here or there, it doesn't make any difference ... I am home to cook and look after the kids and he's out working". 
Couple relationships are also regulated by the same traditional values and principles, according to which spouses should not fight and should avoid misunderstandings; more specifically, women should stand in silence, as taught by their mothers and in-laws. Even after migration, both spouses need to respect a fundamental principle:

"Wives need to do as their husbands say, men, on their side, need to make their wives happy."

"There's no fighting, couples shouldn't argue."

"Most of all you need to endure and carry on, that's all."

Rather than being viewed as a chance to exchange ideas, arguments and fights are considered signs of weakness and fault, and therefore should be avoided at all costs. In this respect, all the women in our sample stated they never fight with their husbands.

Despite physically being in Italy, Pakistani couples seem to have left their heart and soul in their homeland and this results in them being isolated, except from contact with their fellow nationals. In this view, it is not a case that many women report not having had any contacts with other Italian families and have very low language proficiency, despite their long stay in the host country. Such feelings are clearly expressed in the following quote:

"Women in Italy are alone, there's no place they can go to vent. In the beginning, it was very hard,

I used to cry a lot, I didn't know anyone, I wasn't meeting anyone and I didn't speak the language.

I even got admitted to hospital."

Another reason for limiting their contact with Italian people is Pakistani women's disapproval of Italian couples' lifestyles and habits, especially with regards to public displays of affection between partners, meetings and dates outside the marriage, as well as the excessive exposure of the female body, perceived as a lack of respect and honorability:

"I don't think it is a fine thing to behave like that [showing affection ed] in public. These things should be done in secret, where you can't be seen."

With regards to family relations, Pakistani women criticize Western cultures for not giving elderly the value and importance they deserve while often abandoning them in the last years of their lives; in the same line of thoughts, the high divorce rates and their spoiling of the family stability and unity are highly condemned.

Finally, Italian families are severely criticized for their consumerist orientation that leads them to overlook children while devoting most of their time to work, in the hope of increasing their purchasing power. Western consumerism is viewed as the main cause of family disruption, hence the need to hold on to more traditional values and habits:

"Italy is going through difficult times ... you have lost the value of family. Men work, women work too ... I don't think Italian couples are happy ... who's looking after the children? And what about the elderly? They are alone the whole day, they spend way too much time alone."

\subsubsection{Adjustments Required by the Post-Migration Context}

The distance from one's extended family and kin is undoubtedly the greatest and most difficult change for Pakistani immigrant women who, due to migration, are deprived of the social and recreational dimension experienced with the other women of the family. Back in their homeland, women used to stroll around markets in search of goods for themselves or their family, however, such an activity is impossible in Italy due to both the lack of traditional shops as well as the absence of their female network:

"What I like the most about my country is that people are closer to each other. Here, it's not like that,

I miss it very much." 
"If I had to do shopping back there, I would go out with the other women, we would go in different shops, especially when there's the bazar ... there are a lot of people, it's so crowded you can barely move and you can feel there's a festive atmosphere. On the contrary, here you cannot feel this excitement."

Deprived of the protection provided by their extended family and of the solidarity offered by the other women, Pakistani female immigrants to Italy lose most of their negotiating power and often must put up with their husband's choices and will:

"When husbands do not behave well towards their wives, their mothers and fathers will call them and tell them not to do this or that. If things are really bad my parents or brothers would call him too."

After migration, spouses are left alone to resolve their own disputes while extended families' support and mediation is almost absent. In this respect, many women struggle to accept their husbands' sudden closeness, especially in those cases when the arranged wedding resulted in a problematic and unhappy marriage.

On their side, men also seem to face new difficulties after migration: While back in Pakistan responsibilities used to be shared among male family members, in Italy, men are alone to provide for their loved ones' economic well-being. In other words:

"While if you don't work in Pakistan you can still have a house and live well, in Italy you always need to work to support your family."

Both men and women face unexpected and new struggles after migration and the solitude due to the lack of the extended family network places both of them at risk of isolation while charging them of a greater individual responsibility.

"I don't know what it is ... if it's the cultural difference, the different way of thinking ... women don't befriend each other here, we are more friendly. Here, you don't have anyone, no one steps in if you need a hand and we are alone, both of us ... men are alone because they don't have the chance to talk with their brothers and parents and they cannot get any help in case of trouble, they need to do everything on their own."

\subsubsection{Resources of the Post-Migration Context}

Despite most interviewees suffering from the lack of their extended families, some of them reported to have benefitted from this forced distance as they are now solely responsible for managing their own family: They can make decisions according to their own wishes and inclinations and do not have to report to the other women in their husband's family. Men, on their side, might benefit from the fact of not having to mediate between their spouses and their own family. The following statement reports a clear exemplification of the problems faced by men in having to mediate between their spouse and their family:

"It might happen that, on one side, I tell my husband: "your sister/brother did this" and, on the other side, his mother tells him: "your wife did that" ... so it's his responsibility to understand who's right. Should he side with his wife or with his mother? This is a big problem ... he cannot argue with his mother but he cannot argue with his wife either, so he needs to think carefully. This is an issue that might trigger many problems, those who side with their wives will have their parents say: "we raised you, we allowed you to study and now you are leaving us behind?". It is a very complicated role for both the man and the woman."

While being critical towards Western society for many aspects, Pakistani women praise the intimacy and care Italian couple members show each other. In this sense, migration allowed them to explore the affective dimension of their relationship that is generally overlooked in the Pakistani understanding of marriage. 
"Romantic couples are so beautiful: Women please their husbands and men please their wives in return. Here, in Italy, we could see this beautiful thing, this closeness between spouses we are not used to."

\section{Discussion}

The present article reports on the outcomes of research on the everyday life of Moroccan and Pakistani couples immigrated to Italy in the view of 30 Muslim immigrant women. More specifically, the research investigated the changes that have occurred to the couple relationship after migration as well as the variables that might produce such changes. Partners' roles and responsibilities, family mandates, relationships with one's home country and family of origin, values and representations with regards to couple and family life, challenges, and opportunities arose from the encounter with the new culture are therefore studied.

Faced with the challenges posit by the new context, immigrants are called to both restructure their social relationships and gender and marital roles. Traditional representations of gender roles and duties are challenged and religious-based values and beliefs are often in open contrast with the post-modern and secular values of Western countries [14,16,31].

Immigration inevitably leads to contacts and potential clashes among different cultures and require both immigrants and mainstream society members to change to adjust to the new situation. The results of such an adjustment process are far from predictable as they are largely dependent on both personal as well as situational factors $[6,7,9,10]$. While some individuals are willing to integrate adopting values and practices of the host country while at the same time keeping their own, others opt for separation and thus keep their original culture while avoiding contact with the dominant culture. Muslim women, in particular, "present an interesting puzzle" [10] (p. 1622) from the perspective of acculturation and integration: While being regarded both by their families and community members as the guardians of religious values and traditions, they can contemporarily promote adaptation to the mainstream culture thanks to their involvement in social and community activities or their use of community services [10,22]. In her research on Muslim immigrants to America, Wang [22] found that women maintained a certain degree of separation from the mainstream community and kept their cultural identity (especially with regards to religion and housing) while at the same time functioning and interacting with the host society on a daily basis. In this perspective, Muslim immigrant women act as bridges between cultures by adopting new and creative acculturation strategies that seem to combine both separation and integration.

While being characterized by some peculiarities and specificities depending on the story of each couple, the interviewed women's narratives seem to replicate such a strategy. However, key differences between Moroccan and Pakistani interviewees need to be acknowledged.

More specifically, Moroccan women are more heterogeneous in their representations and experiences while, on the contrary, all the Pakistani immigrants in our sample share the same views and opinions on couple relationships and on the duties and responsibilities of each partner.

In this respect, it seems important to note that the significant changes that have occurred over the past 20 years have lead modern Morocco towards a different balance between tradition and change, one in which influences from the Western countries are far more evident [78-81].

Despite the afore-mentioned changes allowing Morocco to take a leap into modernity, profound differences between urban and rural families still exist. While urban families have gone from including extended family members to only being constituted of one unit with few children, rural families have maintained a more traditional structure and weddings are arranged by perspective spouses' families of origin [82].

Despite the afore-mentioned great within group variability, Moroccan interviewees praise and maintain the principles and attitudes acquired in their country of origin with respect to couple life and women's duties: Values and meanings attached to marriage and couple relationships are therefore reactualized in the host country. Such a result is consistent with previous findings showing that, 
despite Moroccan immigrant women enjoying the financial, educational, and social benefits brought about by migration, they still stick to traditional values, such as honor and family [53].

Another interesting element that emerged from some interviews is the shift towards more conservative values and habits observed in many Muslim female immigrants: While their renewed interest and commitment towards traditional values and customs might be interpreted as an attempt to find comfort, belonging, and protection from social isolation $[1,16]$, it might as well be the result of specific diaspora policies carried out by local governments and aimed at strengthening national identity while minimizing regional differences [83]. A clear exemplification of the above-mentioned shift towards conservatism is the Moroccan women's use of the veil: Abandoned in the country of origin, the hijab is used in the immigration country both as a symbol of belonging as well as for protection.

Irrespectively of their country of origin, all the women in our sample valued religion: Religious values do not simply concern one's spiritual life, they also regulate men and women's conduct and lifestyle. Islamic faith deeply permeates every aspect of one's social and private life and, in this perspective, it shapes and informs the behaviors, values, attitudes, and roles partners take on in their couple relationship [84]. While religious identity can provide protection and a sense of belonging and help women process the disorientation caused by migration, it may also consolidate traditional gender roles and prevent or slow integration $[6,10,14,16]$. However, while explaining the maintenance of one's culture of origin, the retention of one's religious values and practices per se does not justify distancing from the host culture. As underlined by some scholars [13], Muslim's reduced acculturation is the result of the strive to maintain one's cultural and religious identity in a hostile and discriminatory context. Therefore, acculturation is mediated by the perception of the distance between one's beliefs and values and those of the host country. In this respect, all the interviewees acknowledged a great difference in the functions, duties, and positioning of women in Western societies if compared to their own: Women find their value and fulfillment in being good wives and mothers and in taking care of their husbands and offspring. While clearly perceiving the cultural gap between their own culture and that of the host country, Moroccan women appreciate some practices and habits in use in the new context. Despite being critical towards the increasing divorce rates in Western societies, Moroccan women praise the mutual support and intimacy couples enjoy in the immigration country. In this view, migration allowed some of these women to encounter, and in a few cases to experience, a different set of values and ways of organizing and regulating couple relationships. Such a finding is consistent with previous studies showing how the encounter with the hosting culture and the lack of their extended families' support resulted in a greater intimacy and closeness between immigrant couple members [7].

While women from both countries seem to hold reference models endorsing the traditional division of roles along gender lines, differences in our interviewees' discourses can be found with respect to the gains and challenges experienced during migration and the adjustments made in order to respond to such challenges. Moroccan immigrants are more likely to have come to terms with the changes imposed by the immigration context. In this perspective, the need, for some Moroccan women to work to support their families is paired with an, at least partial, renegotiation of the partners' duties. However, such a change in their everyday lifestyle and routine does not seem to be associated with a parallel modification of their value system that places women in a subordinate position and sees them as being in charge of the house and the family. Moroccan women in our sample, therefore, seem to use a situational acculturation model: they hold onto their cultural identity while selectively adapting to the new culture [9].

While migration allowed a greater balance and equity among Moroccan couples, the same is not true for their Pakistani counterparts. According to our interviewees, men in Pakistani couples are still the sole breadwinners while women remaining in the safety of their homes is seen as the sole way to preserve and pass along the traditional values acquired in the country of origin. Women's identities revolve around their roles as wives and mothers, and, even in the immigration country, they serve as representatives and custodians of the Pakistani culture. Their attitudes and behaviors are not changed 
by migration, the sole exception being their "forced autonomization" resulting from the need to carry out everyday tasks (i.e., doing the shopping, taking the children to school, etc.) without the support of their female kin-based extended network.

The few studies on female Pakistani immigrants confirm the key role of women in preserving traditional values and keeping customs and rituals alive [26]. In this respect, the maintenance of a rigid role division, along with the respect of religious principles, is essential not only for the individual family, but for the life of the community as a whole. Such a tendency to preserve cultural values by abiding by a traditional lifestyle might result in an increased risk of marginalization and social isolation as well as in a growing pressure and control put on women by their local communities. While it is true that conservatism and attachment to one's culture may lead to isolation, the contrary is also true: A tendency toward conservatism and the assertion of one's cultural identity might be the consequence of discriminatory or marginalizing attitudes by the host society [14,17].

While Islamic religion is a common factor unifying most Pakistani immigrants, regional differences connected to ethnicity and kinship need to be acknowledged. In this respect, Pathan-Pakistanis (the major Pakistani ethic group in Italy) have proven to be the most conservative in their attempt to hold to traditional values and limit external influences [85].

Family is another key value according to our Pakistani interviewees: Obedience and dedication serve as principles regulating relationships among generations and the distance posit by migration does not affect such firm beliefs. The central role played by the family in regulating all aspects of life is clearly evidenced in all the studies on Pakistani immigrants $[49,63]$. In this respect, while men are responsible for ensuring the family's financial stability and livelihood, older female family members (i.e., mothers, mothers in law) make decisions about the house management, children upbringing, and to take care of the material and spiritual well-being of all family members [86]. The lack of such a collective dimension leaves both Pakistani men and women alone to struggle with the challenges of migration, thus resulting, especially for women, in feelings of isolation. Deprived of the support of their female network and unable, due to linguistic and cultural barriers, to establish significant relationships with indigenous people, Pakistani women immigrated to Italy hardly have any chance to voice their feelings and needs.

The acknowledgement of such marginalization and isolation is particularly important as those feelings have been found to be associated to an increased risk of domestic violence among immigrant women $[87,88]$.

While several studies have reported feelings of isolation and marginalization among immigrants (especially when women) [60,88,89], some scholars have also found an increased closeness between immigrant Pakistani spouses following significant life events, such as childbirth, along with a tendency of Pakistani women to maintain gender-based support systems even by seeking advice and contact with local, non-immigrant women $[7,63]$.

While both, Pakistani and Moroccan women, praise the closeness, intimacy, and equalitarian role division of Italian couples, they seem to hold different reference models and representations with respect to their couple relationship. Moroccan couples go through a largely unintentional and yet decisive transformation of their relational models. The distance from their families and kin is paired with a greater individual autonomy and responsibility for women and an increased intimacy and mutual investment for both spouses. Such a gap between a more modern and flexible lifestyle and the maintenance of traditional cultural models closely mirrors a tendency in Moroccan society, in which the changes in the Mowadawana, higher female education, and employment rates are contrasted with courts drawing upon traditional interpretation and practices [53].

On the contrary, the Pakistani women in our sample replicate the same relational patterns they had acquired in their home country, thus exporting their cultural values and heritage to the host country. In this perspective, couple relationships assume the form of contracts, according to which each partner is assigned some gender specific task, as dictated by tradition and taught by the families of origin. 
Although innovative, this study has several limitations, especially with respect to representativeness: Women attending religious or cultural centers, being in contact with members of the host culture, and accepting to be interviewed by Italian researchers probably enjoy a certain degree of freedom and autonomy, have a good language proficiency, are more likely to value cultural exchange, and are, therefore, more likely to adjust to the hosting culture. Moreover, this study did not use any standardized measure to assess participants' acculturation. Besides using quantitative measures, future studies on the topic should also include follow-up assessments to monitor the changes in the participants' accounts and representations over time.

Author Contributions: All the three authors contributed to the study design and conceptualization. Similarly, data collection and analysis have been carried out by all the authors, as indicated in the method section of the paper. The first draft of the paper was prepared by the second (C.G.) and third (M.G..) author and subsequently translated and revised by the first author (A.M.). All the authors contributed to the amendment and improvement of subsequent drafts and approve the submission of this document.

Funding: This research received no external funding

Conflicts of Interest: The authors declare no conflict of interest.

\section{References}

1. Bhugra, D.; Becker, M.A. Migration, cultural bereavement and cultural identity. World Psychiatry 2005, 4, 18-24. [PubMed]

2. Berry, J.W. Immigration, acculturation, and adaptation. Appl. Psychol.-Int. Rev. 1997, 46, 5-68. [CrossRef]

3. Melucci, A. Nomads of the Present: Social Movements and Individual Needs in Contemporary Society; Temple University Press: Philadelphia, PA, USA, 1989; ISBN 978-0877225997.

4. Nathan, T. L'influence qui Guérit, 1st ed.; Odile Jacob: Paris, France, 1994; ISBN 9782738109736.

5. Sluzki, C.E. Migration and family conflict. Fam. Process 1979, 18, 379-390. [CrossRef] [PubMed]

6. Al Wekhian, J. Acculturation process of Arab-Muslim immigrants in the United States. Asian Cult. Hist. 2016, 8, 89-99. [CrossRef]

7. Giuliani, C.; Tagliabue, S. Exploring identity in Muslim Moroccan and Pakistani immigrant women. Eur. J. Psychol. 2015, 11, 63-78. [CrossRef] [PubMed]

8. Giuliani, C.; Tagliabue, S.; Regalia, C. Psychological well-being, multiple identities, and discrimination among first and second generation immigrant Muslims. Eur. J. Psychol. 2018, 14, 66-87. [CrossRef]

9. Khawaja, N.G. Acculturation of the Muslims settled in the West. J. Muslim Ment. Health 2016, 10. Available online: https: / / eprints.qut.edu.au/96293/3/96293.pdf (accessed on 31 October 2018). [CrossRef]

10. Ozyurt, S.S. The selective integration of Muslim Immigrant women in the United States: Explaining Islam's paradoxical impact. J. Ethn. Migr. Stud. 2013, 39, 1617-1637. [CrossRef]

11. Sirin, S.R.; Fine, M. Hyphenated selves: Muslim American youth negotiation identities on the fault lines of global conflict. Appl. Dev. Sci. 2007, 11, 151-163. [CrossRef]

12. Schwarz, S.J. The role of identity in acculturation among immigrant people: Theoretical propositions, empirical questions, and applied recommendations. Hum. Dev. 2006, 49, 1-30. [CrossRef]

13. Gattino, S.; Miglietta, A.; Rizzo, M.; Testa, S. Muslim acculturation in a catholic country: Its associations with religious identity, beliefs, and practices. J. Cross-Cult. Psychol. 2016, 47, 1194-1200. [CrossRef]

14. Saroglou, V.; Mathijsen, F. Religion, multiple identities, and acculturation: A study of Muslim immigrants in Belgium. Arch. Psychol. Relig. 2007, 29, 177-198. [CrossRef]

15. Aprahamian, M.; Kaplan, D.; Windham, A.; Sutter, J.; Visser, J. The relationship between acculturation and mental health of Arab Americans. J. Ment. Health Couns. 2011, 33, 80-92. [CrossRef]

16. Ozyurt, S.S. Living Islam in Non-Muslim Spaces: How Religiosity of Muslim Immigrant Women Affect Their Cultural and Civic Integration in Western Host Societies; The Center for Comparative Immigration Studies: San Diego, CA, USA, 2009; Available online: https:/ /www.researchgate.net/publication/237374975_Living_ Islam_in_Non-Muslim_Spaces_How_Religiosity_of_Muslim_Immigrant_Women_Affect_Their_Cultural_ and_Civic_Integration_in_Western_Host_Societies (accessed on 31 October 2018).

17. Klausen, J. The Islamic Challenge: Politics and Religion in Western Europe; Oxford University Press: New York, NY, USA, 2005; ISBN 9780199231980. 
18. Barry, D.T. Measuring acculturation among male Arab immigrants in the United States: An exploratory study. J. Immigr. Health 2005, 7, 179-184. [CrossRef] [PubMed]

19. Friedman, M.; Saroglou, V. Religiosity, psychological acculturation to the host culture, self-esteem and depressive symptoms among stigmatized and non-stigmatized religious immigrant groups in Western Europe. Basic Appl. Soc. Psych. 2010, 32, 185-195. [CrossRef]

20. Gordon, M. Assimilation in American Life; Oxford University Press: New York, NY, USA, 1964; ISBN 9780195008968.

21. Kim, Y.Y. Intercultural personhood: Globalization and a way of being. Int. J. Int. Rel. 2008, 32, 359-368. [CrossRef]

22. Wang, E. Identity and Self Reflection: Six Arab Muslim Immigrant Women Tell Their Stories. Ph.D. Thesis, University f Michigan-Dearborn, 2017. Available online: https:/ / deepblue.lib.umich.edu/handle/2027.42/ 136072 (accessed on 29 October 2018).

23. Pew Research Center. Mainstream and Moderate Attitudes; Muslim Americans: No signs of Growth in Alienation or Support for Extremism. Available online: http:/ / www.pewforum.org/2011/08/30/muslim-americans-nosigns-of-growth-in-alienation-or-support-for-extremism/ (accessed on 29 October 2018).

24. Haddad, Y.Y.; Moore, K.M.; Smith, J.I. Muslim Woman in America: The Challenge of Islamic Identity Today; Oxford University Press: New York, NY, USA, 2006; ISBN 978-0199793341.

25. Predelli, L.N. Interpreting gender in Islam: A case study of immigrant Muslim women in Oslo, Norway. Gend. Soc. 2004, 18, 473-493. [CrossRef]

26. Giuliani, C.; Olivari, M.G.; Alfieri, S. Being a "Good" Son and a "Good" Daughter: Voices of Muslim Immigrant Adolescents. Soc. Sci. 2017, 6, 142. [CrossRef]

27. Ross-Sheriff, F. Immigrant Muslim women in the United States: Adaptation to American society. Soc. Work Res. 2001, 2, 283-294.

28. Salih, R. Gender in Transnationalism: Home, Longing and Belonging among Moroccan Migrant Women, 1st ed.; Routledge: London, UK, 2003; ISBN 978-0415267038.

29. Ataca, B.; Berry, J.W. Psychological, sociocultural, and marital adaptation of Turkish immigrant couples in Canada. Int. J. Psychol. 2002, 37, 13-26. [CrossRef]

30. Hyman, I.; Guruge, S.; Mason, R. The impact of migration on marital relationships: A study of Ethiopian immigrants in Toronto. J. Comp. Fam. Stud. 2008, 39, 149-163.

31. Yu, Y. Reconstruction of gender role in marriage: Processes among Chinese immigrant wives. J. Comp. Fam. Stud. 2011, 42, 651-668. Available online: https:/ / www.jstor.org/stable/41604477f (accessed on 27 June 2018).

32. Daneshpour, M. Couple therapy with Muslims: Challenges and opportunities. In Multicultural Therapy; Mudita, R., Volker, T., Eds.; Sage Publications: Los Angeles, CA, USA, 2009; pp. 103-120. [CrossRef]

33. Daneshpour, M.; Fathi, E. Muslim Marriages in the Western World: A Decade Review. J. Muslim Ment. Health 2016, 10, 51-64.

34. Douglas, A.; Springer, P.R.; Hollist, C.S. Therapy with immigrant Muslim couples: Applying culturally appropriate interventions and strategies. J. Couple Relatsh. Ther. 2012, 11, 254-266. [CrossRef]

35. McGoldrick, M.; Giordano, J.; Garcia-Preto, N. (Eds.) Ethnicity and Family Therapy, 3rd ed.; The Guilford Press: New York, NY, USA, 2005; ISBN 978-1593850203.

36. Sabatier, C. Ethnic and national identity among second-generation immigrant adolescents in France: The role of social context and family. J. Adolesc. 2008, 31, 185-205. [CrossRef] [PubMed]

37. Vedder, P.; Sam, D.L.; Liebkind, K. The acculturation and adaptation of Turkish adolescents in North-Western Europe. Appl. Dev. Sci. 2007, 11, 126-136. [CrossRef]

38. Pew Research Center. The Future of World Religions: Population Growth Projections, 2010-2050; Pew Research Center: Washington, WA, USA, 2010; Available online: http://www.pewforum.org/2015/04/02/religiousprojections-2010-2050/ (accessed on 18 August 2018).

39. Pew Research Center. Europe's Growing Muslim Population; Pew Research Center: Washington, WA, USA, 2017. Available online: http:/ / www.pewforum.org/2017/11/29/europes-growing-muslim-population/ (accessed on 18 August 2018).

40. Istituto Nazionale di Statistica (Istat). Appartenenza e Pratica Religiosa tra i Cittadini Stranieri; Istat: Rome, Italy, 2016. Available online: https:/ / www.istat.it/it/files/ /2015/10/Religione-tra-gli-stranieri.pdf (accessed on 20 July 2018). 
41. Fondazione Ismu. Ventiduesimo Rapporto Sulle Migrazioni 2016; Franco Angeli Editore: Milan, Italy, 2017.

42. Istituto nazionale di statistica (Istat). Stranieri residenti al $1^{\circ}$ gennaio 2017; Istat: Rome, Italy, 2018. Available online: http:/ / dati.istat.it/Index.aspx?DataSetCode=DCIS_POPSTRRES1 (accessed on 18 August 2018).

43. Ministero del lavoro e delle politiche sociali (ML). La comunità Pakistana in Italia. Rapporto 2017; ML: Rome, Italy, 2017. Available online: http:/ / www.integrazionemigranti.gov.it/rapportiricercaimmigrazione/ RapportiNazionali/2017RCPakistan.pdf (accessed on 1 May 2018).

44. Ministero del lavoro e delle politiche sociali (ML). La Comunità Marocchina in Italia. Rapporto 2017; ML: Rome, Italy, 2017. Available online: http://www.lavoro.gov.it/documenti-e-norme/studi-estatistiche/Documents / Rapporti\%20annuali\%20sulle\%20comunit\%C3\%A0\%20migranti\%20in\%20Italia\% 20-\%20anno\%202017/Marocco-Report-2017.pdf (accessed on 1 May 2018).

45. De Haas, H. Morocco's Migration Experience: A Transitional Perspective. Int. Migr. 2007, 45, 39-70. [CrossRef]

46. Giunchi, E. Lo stato islamico in Pakistan tra realtà e finzione. In Lo stato Islamico: Teoria e Prassi nel Mondo Contemporaneo, 1st ed.; Montessoro, F., Ed.; Guerini Editore: Milano, Italy, 2005; pp. 141-168, ISBN 8883356578.

47. Giunchi, E. Donne e diritto di famiglia in Pakistan, Marocco e Egitto. Un profilo storico-giuridico. In Esperienze di Donne Nella Migrazione Araba e Pakistana, 1st ed.; Regalia, C., Giuliani, C., Eds.; Franco Angeli Editore: Milano, Italy, 2012; pp. 13-33, ISBN 9788856848250.

48. Hermansen, M.K. Two-way acculturation: Muslim women in America between individual choice (liminality) and community affiliation (communitas). In The Muslims of America, 1st ed.; Haddad, Y.Y., Ed.; Oxford University Press: New York, NY, USA, 1991; pp. 188-201, ISBN 9780195085594.

49. Zaman, R.M.; Zaman, T.R.; Stewart, S.M. Pakistan: Culture, community, and filial obligations in a Muslim society. In Families Across Cultures: A 30-Nation Psychological Study, 1st ed.; Georgas, J., Berry, J.W., Van de Vijver, F.J., Kagitçibasi, Ç., Poortinga, Y.H., Eds.; Cambridge University Press: Cambridge, UK, 2006; pp. 427-434, ISBN 9780521529877.

50. World Health Organization (WHO). Regional Health Systems Observatory-EMRO; WHO: Geneva, Switzerland, 2016; Available online: http:/ / applications.emro.who.int/dsaf/EMROPUB_2016_EN_19169.pdf?ua=1\&ua= 1 (accessed on 1 September 2018).

51. World Health Organization (WHO). Eastern Mediterranean Region, EMROPUB; WHO: Geneva, Switzerland, 2016; Available online: http:/ / applications.emro.who.int/dsaf/EMROPUB_2016_EN_19169.pdf?ua=1\&ua= 1 (accessed on 1 September 2018).

52. Hassouneh-Phillips, D.S. Marriage is Half of Faith and the Rest is Fear Allah. Marriage and Spousal Abuse Among American Muslims. Violence Against Women 2001, 7, 927-946. [CrossRef]

53. Pham, P.T.D. Moroccan Immigrant Women in Spain: Honor and Marriage; Lexington Books: Plymouth, UK, 2013; ISBN 978-0739183915.

54. Ammar, N.H. Wife battery in Islam: A comprehensive understanding of interpretations. Violence Against Women 2007, 13, 516-526. [CrossRef]

55. Zaidi, A.U.; Shuraydi, M. Perceptions of arranged marriages by young Pakistani Muslim women living in a Western society. J. Comp. Fam. Stud. 2002, 33, 495-514.

56. Ahmadi, N. Migration challenges views on sexuality. Ethn. Racial Stud. 2003, 26, 684-706. [CrossRef]

57. Abu-Ras, W. Cultural beliefs and service utilization by battered Muslim immigrant women. Violence Against Women 2007, 13, 1002-1028. [CrossRef] [PubMed]

58. Bodman, H.L.; Tohidi, N.E. (Eds.) Women in Muslim Societies: Diversity within Unity; Lynne Rienner Publishers: Boulder, CO, USA, 1998; ISBN 978-1-55587-578-7.

59. Giuliani, C.; Gennari, M. Intimate Male Partner Violence and Muslim migration [Intimate Male Partner Violence: Voci dei migranti musulmani]. Maltrattamento e Abuso all'Infanzia 2014, 16, 101-112. [CrossRef]

60. Gennari, M.; Giuliani, C.; Accordini, M. Muslim Immigrant Men's and Women's Attitudes Towards Intimate Partner Violence. Eur. J. Psychol. 2017, 13, 688-707. [CrossRef] [PubMed]

61. Levitt, H.M.; Ware, K.N. Religious leaders' perspectives on marriage, divorce and intimate partner violence. Psychol. Women Q. 2006, 30, 212-222. [CrossRef] 
62. Adam, N.M.; Schewe, P.A. A multilevel framework exploring domestic violence against immigrant Indian and Pakistani women in the United States. J. Muslim Ment. Health 2007, 2, 5-20. [CrossRef]

63. Qureschi, R.I.; Pacquiaio, D.F.; Diegmann, E.K. Cultural practices of Pakistani immigrant women during pregnancy and childbirth. Online J. Cult. Competence Nurs. Healthcare 2016, 6, 83-91. [CrossRef]

64. Critelli, F.M. Beyond the veil in Pakistan. Affilia 2010, 25, 236-249. [CrossRef]

65. Kulwicki, A.D. The practice of honor crimes: A glimpse of domestic violence in the Arab world. Issues Ment. Health Nurs. 2002, 23, 77-87. [CrossRef]

66. Gill, D.S.; Matthews, B. Changes in the breadwinner role: Punjabi families in transition. J. Comp. Fam. Stud. 1995, 26, 255-263.

67. Yllmaz, F. From immigrant worker to Muslim immigrant: Challenges for feminism. Eu. J. Women's Stud. 2015, 22, 37-52. [CrossRef]

68. Elhaïli, S.; Lasry, J.C. Pouvoir conjugal, rôles sexuels et harmonie maritale chez des couples immigrants Marocains à Montréal. Rev. Qué. Psychol. 1998, 19, 233-250.

69. Yick, A.G. Feminist theory and status inconsistency theory: Application to domestic violence in Chinese immigrant families. Violence Against Women 2001, 7, 545-562. [CrossRef]

70. Efe, S.; Ayaz, S. Domestic violence against women and women's opinions related to domestic violence. Anatol. J. Psychiatry 2010, 11, 23-29.

71. Menonna, A. La presenza musulmana in Italia; Fondazione Ismu: Milan, Italy, 2016. Available online: http:/ / www.ismu.org/wp-content/uploads/2016/07/Menonna_Musulmani_Fact-sheet_Giugno20161.pdf (accessed on 1 July 2018).

72. Roggeband, C.; Verlo, M. Dutch women are liberated, migrant women are a problem: The evolution of policy frames on gender and migration in the Netherlands (1995-2005). Soc. Policy Admin. 2007, 41, 271-288. [CrossRef]

73. Choak, C. Asking questions: Interviews and evaluations. In Research and Research Methods for Youth Practitioners; Bradford, S., Cullen, F., Eds.; Routledge: London, UK, 2012; pp. 90-112.

74. Braun, V.; Clarke, V. Using thematic analysis in psychology. Qual. Res. Psychol. 2006, 3, 77-101. [CrossRef]

75. Muhr, T. Atlas.ti 5.0 Computer Software; Scientific Software Development: Berlin, Germany, 2004.

76. Friese, S.; Soratto, J.; Pires, D. Carrying out a computer-aided thematic content analysis with ATLAS.ti. MMG Working Paper, 2018 (18-02). Available online: http:/ / www.mmg.mpg.de/fileadmin/user_upload/ documents/wp/WP_18-02_Friese-Soratto-Pires_AtlasTI.pdf (accessed on 1 September 2018).

77. Brislin, R.W. Back-translation for cross-cultural research. J. Cross Cult. Psychol. 1970, 1, 185-216. [CrossRef]

78. Belhatti, H.M. Marocco, 1st ed.; Pendragon: Bologna, Italy, 2000; ISBN 978-8-8834-2036-8.

79. Bravin, A. Marocco. Città Imperiali, Castelli di Terra e Oasi del sud; Polaris: Firenze, Italy, 2001; ISBN 8886437552.

80. Mernissi, F. Islam e Democrazia. La Paura Della Modernità, 2nd ed.; Giunti Gruppo Editoriale: Florence, Italy, 2002; ISBN 8809028333.

81. El Khayat, R. Cittadine del Mediterraneo. Il Marocco Delle Donne; Castelvecchi: Rome, Italy, 2009; ISBN 8876152806.

82. Habouss, H. Il Marocco ieri e oggi: Una nota introduttiva. In Nato in Marocco, Immigrato in Italia. Parlano $i$ Marocchini che Vivono nel Nostro Paese; Bruno Ventre, A., Ed.; Arcisolidarietà Ambiente: Roma, Italy, 1995.

83. INTERACT Research Report, 2015/10. Maintaining National Culture abroad Countries of Origin, Culture and Diaspora. Available online: http:/ / cadmus.eui.eu/bitstream/handle/1814/35881/INTERACT-RR-2015_ 10_Culture.pdf;sequence=1 (accessed on 1 September 2018).

84. Saint-Blancat, C. (Ed.) L'Islam in Italia.Una Presenza Plurale; Edizioni Lavoro: Rome, Italy, 1999; ISBN 9788879108744.

85. Fijac, B.M.; Sonn, C.C. Pakistani-Muslim immigrant women in Western Australia: Perceptions of identity and community. Network 2004, 16, 18-27.

86. Ali, T.S.; Krantz, G.; Gul, R.; Asad, N.; Johansson, E. Gender roles and their influence on life prospects for women in urban Karachi, Pakistan: A qualitative study. Glob. Health Action 2011, 4, 1-9. [CrossRef]

87. Colorado-Yohar, S.; Tormo, M.J.; Salmerón, D.; Dios, S.; Ballesta, M.; Navarro, C. Violence reported by the immigrant population is high as compared with the native population in southeast Spain. J. Interpers. Violence 2012, 27, 3322-3340. [CrossRef] 
88. Poteyeva, M.; Wasileski, G. Domestic Violence against Albanian Immigrant Women in Greece: Facing Patriarchy. Soc. Sci. 2016, 5, 37. [CrossRef]

89. Thimm, V. Muslim Mobilities and Gender: An Introduction. Soc. Sci. 2018, 7, 5. [CrossRef]

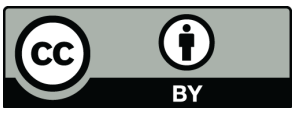

(C) 2018 by the authors. Licensee MDPI, Basel, Switzerland. This article is an open access article distributed under the terms and conditions of the Creative Commons Attribution (CC BY) license (http://creativecommons.org/licenses/by/4.0/). 